\title{
Significant Restenosis of Multiple Saphenous Vein Grafts Early After Coronary Artery Bypass Graft Surgery: a Case Report
}

\author{
Davran Cicek ${ }^{\mathrm{a}, \mathrm{c}}$, Seher Gokay ${ }^{\mathrm{a}}$, Haldun Muderrisoglu ${ }^{\mathrm{b}}$
}

\begin{abstract}
Despite the benefits of Coronary Artery Bypass Graft surgery, 15\% to $25 \%$ of patients develop graft closure within one year following the procedure. The patency rate of grafts mainly predicts both the short- and long-term benefit from surgery. Here we report a patient diagnosed as acute coronary syndrome five months after surgery with significant stenosis of multiple saphenous vein grafts.
\end{abstract}

Keywords: Coronary Artery Bypass Graft Surgery; Saphenous Vein Grafts; Restenosis

\section{Introduction}

Coronary angioplasty has become a mainstay in the treatment of ischemic heart disease in the last decade, but it is not a relevant modality in patients with significant $(\geq 50 \%)$ left main coronary artery disease (LMCD). On the other hand, Coronary Artery Bypass Graft (CABG) surgery has been demonstrated in both observational and randomized trials to prolong survival in those patients [1]. Despite the benefits of CABG surgery, $15 \%$ to $25 \%$ of patients develop graft closure within one year following the procedure [2]. Furthermore, the patency rate of grafts mainly predicts both the short- and long-term benefit from CABG surgery [3]. Ischemia after

Manuscript accepted for publication June 30, 2011

${ }^{a}$ Department of Cardiology, Başkent University School of Medicine, Antalya, Turkey

${ }^{\mathrm{b}}$ Department of Cardiology, Baskent University School of Medicine, Bahcelievler, No: 1, Ankara, Turkey

${ }^{\mathrm{c}}$ Corresponding author: Department of Cardiology, Baskent University School of Medicine, Saray Mah, Yunusemre cad, No: 1 07400,

Antalya, Turkey. E-mail: davrancicek@mynet.com
CABG may be due to new disease, progression beyond the bypass graft anastomosis, or disease in the graft itself [4]. Teixeira et al. reported that a history of CABG was an independent predictor for a future readmission for unstable angina, and they found the time between CABG surgery and the acute coronary syndrome (ACS) to vary between a median of 4 to 12.5 years [5]. The present paper reports an ACS patient five months after CABG surgery.

\section{Case Report}

A 60-year-old Caucasian male presented to our hospital complaining of typical chest pain, which started approximately a year ago, and worsened in the last few days. Additionally, he had nocturnal angina three days before admission. He also had (New York Heart Association) NYHA II dyspnoea. He denied any palpitation, syncope or sweating. He has been taking a beta-blocker for hypertension and acetylsalicylic acid for primary prevention of coronary artery disease (CAD). He used to smoke for many years until he quit 6 or 7 years ago. He has a family history of CAD (his brother died from MI). His other risk factors included hypertension and hyperlipidaemia. His physical examination was non-remarkable except for an S4. Electrocardiography did not reveal any ischemic changes. Echocardiography showed moderate hypokinesis of the apical septum and mild mitral regurgitation. We diagnosed the patient with ACS and performed coronary angiography (CAG) which revealed 70$80 \%$ stenosis of LMCA, $60 \%$ stenosis at the ostium of diagonal, $70 \%$ stenosis of the major obtuse marginalis (Fig. 1a, b) and $70 \%$ mid-right coronary artery (RCA) stenosis (Fig. 2). Ventriculography was normal. The patient was scheduled for CABG surgery, operated three days after the coronary angiography. Left internal mammary artery (LIMA) to left anterior descending artery (LAD), sapheneous graft to diagonal and major obtuse marginalis by $\mathrm{Y}$ anostomous (Ao-D1-OM-Y anostomous) and sapheneous graft to right coronary artery (Ao-RCA) was performed, and discharged after a week. There was no complication during and after the surgery, and the patient was discharged from the hospital in a good condition. Two months after the surgery, he 

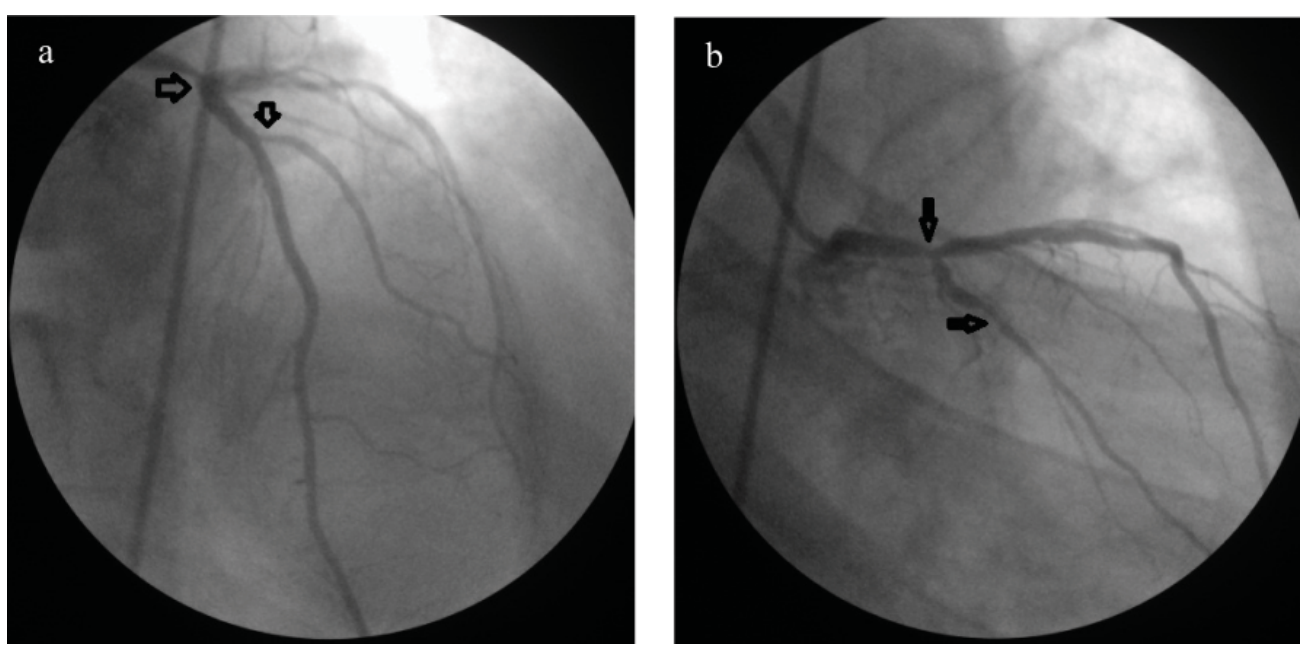

Figure 1. (a) Tubuler stenosis in the left main (70-80\%) and major diagonal (60\%) coronary artery; (b) $70 \%$ stenosis of the major obtuse marginalis.

experienced a chest pain during the night which lasted for 5 minutes. He was re-admitted with the diagnosis of ACS, but his ECG and cardiac enzymes did not show an ischemic event. We performed an exercise treadmill test which did not reveal any ischemic changes. He was discharged and advised to continue his present medications: a beta-blocker, acetylsalicylic acid, a statin and an ACE inhibitor. Five months after the operation, he again applied to the hospital with the complaint of squeezing chest pain. The troponin-I level was high indicating an ischemic injury. A CAG was performed revealing 80\% LMCA stenosis, 70-80\% LAD ostial stenosis, total proximal D1 occlusion, total proximal major OM occlusion, 70\% proximal RCA stenosis, and 98\% crux stenosis. The LAD-LIMA graft was open. There were $90 \%$ stenoses in both of the Aorta-Cx-OM and diaogonal saphenous anastomoses (Fig. 3). A 70\% stenosis was noticed at the proximal ostium of the Aorta-saphenous-RCA anastomosis, and a 98\% stenosis was noticed distal to the saphenous-RCA anastomo-

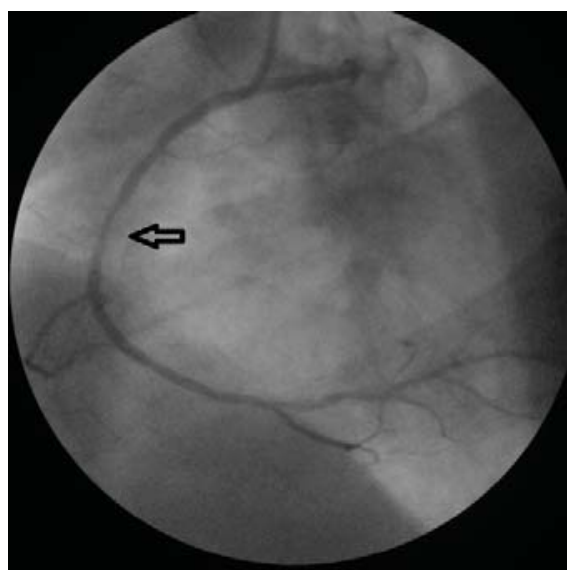

Figure 2. Mid-right coronary artery stenosis. sis point (Fig. 4). A $2.25 \times 12 \mathrm{~mm}$ stent has been implanted to the $\mathrm{D} 1$ lesion following a $1.5 \times 20 \mathrm{~mm}$ balloon angioplasty a $2.5 \times 18 \mathrm{~mm}$ stent has been implanted to the OM1 lesion following a $2.5 \times 12 \mathrm{~mm}$ balloon angioplasty (Fig. 5), a 2.5 $\mathrm{x} 24 \mathrm{~mm}$ stent has been implanted to the lesion distal to the Aorta-saphenous-RCA anastomosis following a $2.5 \times 20 \mathrm{~mm}$ balloon angioplasty, and a $2.5 \times 18 \mathrm{~mm}$ stent has been implanted to the proximal lesion (Fig. 6). After the procedure the patient received intensive care including tirofiban and clopidogrel therapy in addition to his present anti-ischemic therapy. After a five-day therapy the patient was discharged from hospital event free.

\section{Discussion}

An increasing number of patients who have had CABG and later have recurrent ischemia undergo revascularization with

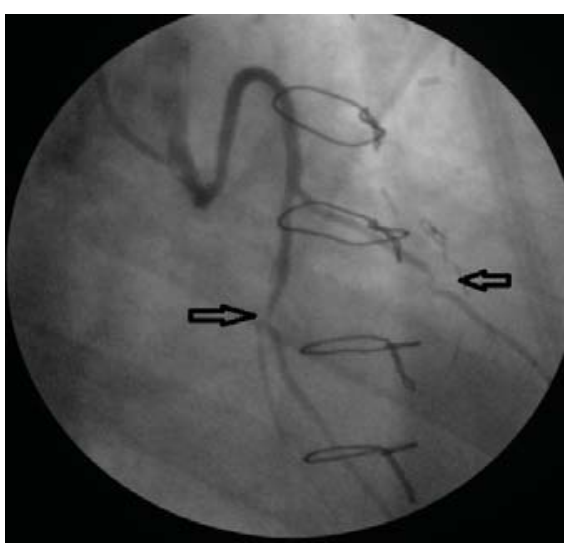

Figure 3. Severe stenosis in both of the Aorta-circumflexobtuse marginalis and diagonal saphenous anastomosis. 


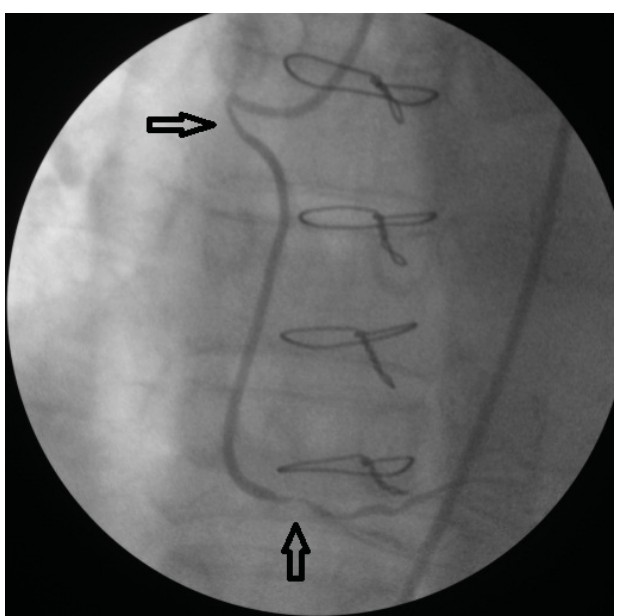

Figure 4. A $70 \%$ stenosis at the proximal ostium and a $98 \%$ stenosis distal to the Aorta-saphenous-right coronary artery anastomosis.

a percutaneous interventional technique [6]. Although data on percutaneous revascularization of saphenous venous grafts are still debated, studies showed no statistical difference in restenosis during a 6-month period, but with an improved clinical outcome for elective stenting [5]. Because of the initial higher mortality of redo $\mathrm{CABG}$ and the comparable long-term mortality, PCI is the preferred revascularization strategy in patients with patent left internal torasic artery (ITA) and amenable anatomy [4]. In the AWESOME RCT and registry, overall in-hospital mortality was higher with CABG than with PCI [7]. A new major coronary event after CABG surgery can be due to progression of atherosclerosis in native arteries and/or development of vascular disease in the graft [5]. Both events were true for this patient, especially with regard to ostial lesions. Experimental studies and observations in patients suggest that the development of dis-

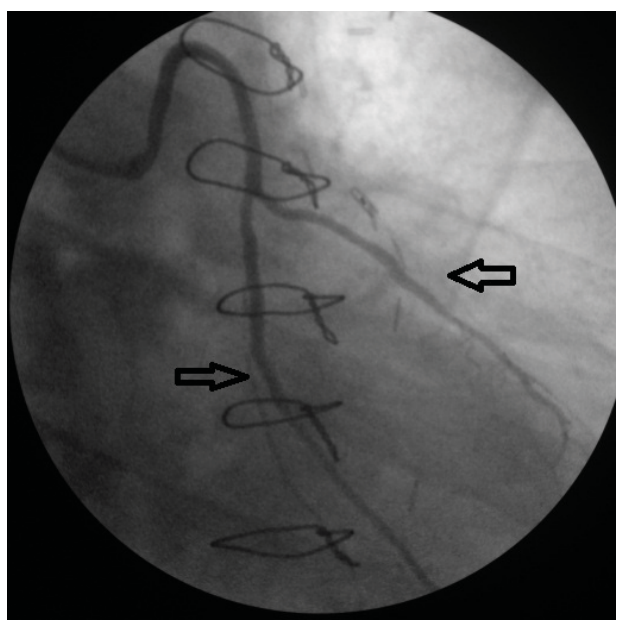

Figure 5. After stent implantation to diagonal and obtuse marginalis sapheneous grafts.

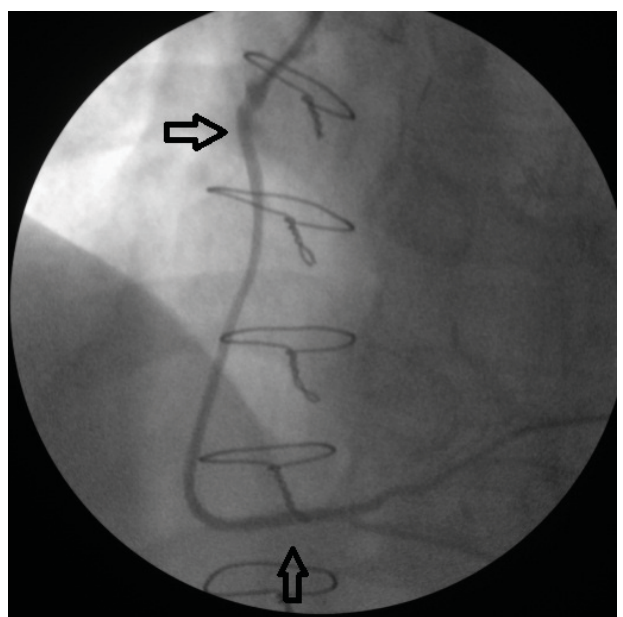

Figure 6. After two stents to proximal and distal Aortasaphenous-RCA anastomosis.

ease in venous aortocoronary artery bypass grafts occurs in several phases. Early occlusion (before hospital discharge) occurs in 8 to 12 percent of venous grafts, and by year, 15 to 30 percent of vein grafts have become occluded [8] Vein grafts that have been implanted in the arteriel circulation for 1 month to 1 year are subject to substantial endothelial denudation and proliferation and to migration of medial cells to the intima. Migration of vascular smooth muscle cells through the internal elastic lamina into the intima may also occur [9]. If the proliferation is severe and localized as may occur at the side of anastomosis between grafts and the recipient artery total occlusion can occur within one year, which is intermediate phase occlusion, as it probably happened in our case we presented. Can LH et al. conducted a study [10] with ACS patients following CABG surgery, and stated that the main reason for ACS was the insufficient patient compliance with regard to the use of statins and ACE inhibitors, with only about $25 \%$ of the patients sticking to their prescribed therapy. Our patient claimed to have been using all of his coronary artery disease medications. His low density lipoprotein (LDL) level, however, was $111 \mathrm{mg} / \mathrm{dL}$ (above $100 \mathrm{mg} / \mathrm{dL}$ ). His statin dose was $20 \mathrm{mg}$, and needed to be increased. Based on previous studies, the role of LDLcholesterol in disease progression in native vessels as well as in by-pass grafts, has been well known [11]. A previous study reported on GGT levels was independently associated with SVG disease. In our case GGT level was normal which was inconsistent with the study [3]. Patients with a history of CABG are reported to be admitted more often for a non-ST-elevation ACS and also to have lower peak values of cardiac biomarkers for necrosis [12]. Our case's cardiac markers were similarly low, the troponin level being 0.362 $\mathrm{ng} / \mathrm{mL}$ (normal $<0.020 \mathrm{ng} / \mathrm{mL}$. According to Crean et al. [12]. this may probably be related to the dual circulation and the more common occlusion of secondary branches is due to the protection of the main coronary arteries by the bypass 
vessels. The case presented here might be of interest for the significantly shorter time interval between the ACS and the prior CABG surgery than the interval varying between the median of 4-12.5 years, as reported in the previous study [5].

\section{Conclusion}

Secondary prevention is as important as primary prevention in coronary artery disease patients. Furthermore, cardiologists should keep in mind that despite all types of preventions acute coronary syndrome can occur within less than one year after $\mathrm{CABG}$.

\section{Conflict of Interest}

The authors declare that they have no competing interests.

\section{Consent}

Written informed consent was obtained from the patient for publication of this case report and accompanying images. A copy of the written consent is available for review by the Editor-in-Chief of this journal.

\section{Authors' contributions}

SB and DC performed the coronary angiography and were major contributors in writing the manuscript. SB, DC and HM worked together in writing the manuscript. All authors read and approved the final manuscript.

\section{References}

1. Caracciolo EA, Davis KB, Sopko G, Kaiser GC, Corley SD, Schaff H, Taylor HA, et al. Comparison of surgical and medical group survival in patients with left main coronary artery disease. Long-term CASS experience. Circulation. 1995;91(9):2325-2334.

2. Okrainec K, Pilote L, Platt R, Eisenberg MJ. Use of cardiovascular medical therapy among patients undergoing coronary artery bypass graft surgery: results from the ROSETTA-CABG registry. Can J Cardiol. 2006;22(10):841-847.

3. Demirkan B, Guray Y, Guray U, Turak O, Hajro E, Korkmaz S. The relationship between saphenous coronary bypass graft occlusion and serum gamma- glutamyltransferase activity. Turk Kardiyol Dern Ars. 2010;38(5):321-326.

4. Wijns W, Kolh P, Danchin N, Di Mario C, Falk V, Folliguet T, Garg S, et al. Guidelines on myocardial revascularization: The Task Force on Myocardial Revascularization of the European Society of Cardiology (ESC) and the European Association for Cardio-Thoracic Surgery (EACTS). Eur Heart J. 2010;31(20):2501-2555.

5. Teixeira R, Lourenco C, Antonio N, Jorge E, Baptista R, Saraiva F, Mendes P, et al. Can we improve outcomes in patients with previous coronary artery bypass surgery admitted for acute coronary syndrome? Rev Esp Cardiol. 2010;63(5):554-563.

6. Mathew V, Clavell AL, Lennon RJ, Grill DE, Holmes $\mathrm{DR}, \mathrm{Jr}$. Percutaneous coronary interventions in patients with prior coronary artery bypass surgery: changes in patient characteristics and outcome during two decades. Am J Med. 2000;108(2):127-135.

7. Morrison DA, Sethi G, Sacks J, Henderson W, Grover F, Sedlis S, Esposito R, et al. Percutaneous coronary intervention versus coronary artery bypass graft surgery for patients with medically refractory myocardial ischemia and risk factors for adverse outcomes with bypass: a multicenter, randomized trial. Investigators of the Department of Veterans Affairs Cooperative Study \#385, the Angina With Extremely Serious Operative Mortality Evaluation (AWESOME). J Am Coll Cardiol. 2001;38(1):143-149.

8. Bourassa MG. Long-term vein graft patency. Curr Opin Cardiol. 1994;9(6):685-691.

9. Bryan AJ, Angelini GD. The biology of saphenous vein graft occlusion: etiology and strategies for prevention. Curr Opin Cardiol. 1994;9(6):641-649.

10. Can LH, Kayikcioglu M, Yavuzgil O, Kultursay H, Soydan I. Evaluation of hospitalization period and fiveyear follow-up of patients admitted with acute coronary syndrome following coronary artery bypass graft surgery. Turk Kardiyol Dern Ars. 2010;38(6):387-392.

11. Campeau L, Enjalbert M, Lesperance J, Bourassa MG, Kwiterovich P, Jr., Wacholder S, Sniderman A. The relation of risk factors to the development of atherosclerosis in saphenous-vein bypass grafts and the progression of disease in the native circulation. A study 10 years after aortocoronary bypass surgery. N Engl J Med. 1984;311(21):1329-1332.

12. Crean PA, Waters DD, Bosch X, Pelletier GB, Roy D, Theroux P. Angiographic findings after myocardial infarction in patients with previous bypass surgery: explanations for smaller infarcts in this group compared with control patients. Circulation. 1985;71(4):693-698. 